\title{
RAZPOREDITEV PREBIVALSTVA V SEVEROVZHODNI SLOVENIJI Z VIDIKA KRAJA BIVANJA IN KRAJA ZAPOSLITVE
}

\author{
Borut Belec*
}

IZVLEČEK

UDK 911.3:314.9(497.12-18)

Članek analizira razmerje med క̌tevilom aktivnega prebivalstva $\mathbf{v}$ kraju bivanja in $\mathbf{v}$ kraju zaposlitve ter razmerje zaposlenih glede na kraj zaposlitve $\mathrm{z}$ namenom ugotavljanja stopnje demogeografske mobilnosti.

\section{ABSTRACT}

UDC 911.3:314.9(497.12-18)

DISTRIBUTION OF POPULATION IN THE NORTH-EASTERN PART OF SLOVENIA FROM THE POINT OF VIEW OF DWELLING AND WORKING PLACE

The article analyses the relation between the number of active population in a dwelling and working place and relation of the employed concerning the working place with the purpose of finding out the degree of demogeographic mobility.

\section{UVOD}

Namen prispevka je izvrednotenje razmerja med ડtevilom aktivnih prebivalcev $\mathbf{v}$ "kraju bivanja" in v "kraju dela" oziroma tamkajšnjimi delovnimi mesti ter razmerje med zaposlenimi v kraju bivanja, v drugem kraju obcine in v drugih obcinah R Slovenije leta 1981. Razen o migracijah v naselja, kjer je več delovnih mest kot aktivnega prebivalstva, lahko po tej poti sklepamo o stopnji gospodarske razvitosti, s primerjavo popisa prebivalstva leta 1991 pa bo mogoce ugotavljati tudi prestrukturiranje gospodarstva in spremembe mobilnosti prebivalstva $\mathbf{v}$ zadnjem desetletju.

Analizo smo opravili na osnovi racunalniškega izpisa podatkov Popisa prebivalstva leta 1981 (Augustinovix, Horvat, Vobovnik, 1991). Z indeksi pojasnjujemo razmerje med stevilom delovnih mest in stevilom aktivnega prebivalstva; pri tem vrednost indeksa nad 100 izkazuje vexje število delovnih mest, kot je aktivnih prebivalcev. Indeksi in odstotkovni deleži se nanaŁajo na 914 oziroma 945 katastrskih obcin (k.o.) SV Slovenije, obe makroregiji, tj. subpanonsko in subalpsko makroregijo, vse mezoregije in mikroregije v njihovi sestavi ter deloma na administrativno razdelitev na občine.

\footnotetext{
- Dr, red.univ.prof, Oddelek za geografijo, Pedagoska fakulteta, Univerza v Mariboru, Koroška cesta 160, 62000 Maribor, Slovenija.
} 


\section{DEJAVNOSTNA SESTAVA PREBIVALSTVA}

SV Slovenija je leta 1981 stela 512.225 prebivalcev, od tega 242.784 aktivnih oseb. Od primarne dejavnosti je živelo 60.525 ali $24,9 \%$ oseb, vendar se subalpska in subpanonska makroregija mox̌no razlikujeta, saj odpade na subpanonsko SV Slovenijo 89,5\% aktivnega kmetijskega prebivalstva in $82 \%$ vseh aktivnih prebivalcev. Delež primarne dejavnosti dosega v subpanonski SV Sloveniji 27,3 \%, v subalpski pa 14,5\%. Najbolj agrarno je Gorixko (75,3\%); precej agrarne so tudi Se Vzhodne Slovenske gorice $(51 \%)$, Haloze $(50,7 \%)$ in Dolinsko $(52,1 \%)$.

Nad povprexjem SV Slovenije po deležu aktivnega neagrarnega prebivalstva, tj. nad $75,1 \%$, so Lendavske gorice $(85,4 \%)$, Dravska ravnina $(81,4 \%)$, Zahodne Slovenske gorice $(76,9 \%)$, Dravinjske gorice $(82,5 \%)$ in vse regije subalpske SV Slovenije s povprecjem $85,5 \%$. V Mislinjski in Dravski dolini je neagrarnega prebivalstva celo $93 \%$.

Sekundarni sektor je v SV Sloveniji zastopan s $40,7 \%$, v subalpskem predelu s $50,6 \%$, v subpanonskem z 38,6 \%; terciarni (20\%) in kvartarni sektor (14\%) pa sta skoraj izenacena. Velika razlika med subpanonsko in subalpsko makroregijo se kaže tudi v gostoti poselitve; ta dosega v prvi $137 \mathrm{lj} / \mathrm{km}^{2}$, v drugi le $63 \mathrm{lj} / \mathrm{km}^{2}$ (povprecje $113 \mathrm{lj} / \mathrm{km}^{2}$ ).

Katastrskih občin $\mathrm{z}$ več kot 50 aktivnimi prebivalci in $\mathrm{z}$ več kot 50 delovnimi mesti je 156 ali $17 \%$, od tega v subpanonskem predelu skoraj dve tretjini. Ni slucajno, da zavzemajo na Dravski ravnini $31,2 \%$ in na Murski ravnini $20 \%$ tamkajšnjih k.o., nasprotno pa v Prekmurskih goricah le $8,8 \%$ k.o.. Razlika, ki nastopa v njihovem deležu med subpanonsko $(13,1 \%)$ in subalpsko makroregijo (25,7 \%), kaže tako tudi na razlixno stopnjo njune gospodarske razvitosti.

\section{REGIONALNA RAZPOREDITEV PREBIVALSTVA GLEDE NA KRAJ BIVANJA IN KRAJ ZAPOSLITVE}

Mobilnost prebivalstva je zaradi stacionarnosti kmetijskega prebivalstva odvisna predvsem od deleža neagrarnega prebivalstva in razporeditve zaposlitvenih zmogljivosti. Dislocirani obrati precej prispevajo $\mathrm{k}$ zmanjß̌anju delovnih migracij iz krajev, kjer se nahajajo, povečajo pa jih iz bližnjih naselij. $\mathrm{Z}$ izločitvijo primarne dejavnosti je zato mogoč $\mathrm{z}$ večjo zanesljivostjo sklepati na stopnjo mobilnosti aktivnega prebivalstva. $\mathrm{S}$ tem namenom analiziramo stevilo in delež aktivnega neagrarnega prebivalstva glede na kraj bivanja in kraj zaposlitve. To razmerje se precej razlikuje od tistega za skupno aktivno prebivalstvo; to je razvidno zlasti na primeru izrazito agrarnih obmoxij.

Katastrske obcine smo glede na indeksno vrednost razdelili v kategorije do 5, 5 - 20, 20 - 50, 50 - 100 in nad 100 (tabela 1, karta 1). Indeks nad 100 prikazuje k.o. $\mathrm{z}$ vec jim stevilom delovnih mest, kot pa znaša Stevilo aktivnih prebivalcev. Vanje so కe zlasti usmerjene delovne migracije. Imajo ga Mariborska mestna regija (130), Lendavske gorice (160), Ravensko (140), Mursko 
(129) in Ptujsko polje (137), odkoder najde prebivalstvo neagrarno zaposlitev predvsem v obxinskih središih. Indeks od 50 - 100 imajo le Vzhodne Slovenske gorice (53), od 20 - 50 pa Goriðko (31), Dolinsko (36), Apaško polje (44), Zahodne Slovenske gorice (41), Dravsko polje (47) in Haloze (38). Indeksa pod 20 nima nobena regija, zato pa Stevilne k.o., iz katerih odhaja na neagrarno zaposlitev 80 do $90 \%$ aktivnega nekmeðkega prebivalstva. Takih k.o. je v SV Sloveniji 78 ali $20 \%$; 151 ali $16 \%$ k.o. ima indeks od 5 - 10, kar 208 ali $23 \%$ pa indeks do 5; 92 ali $10 \%$ k.o. ima celo indeks 0 , to pomeni, da $\mathrm{v}$ njih za aktivno nekmecko prebivalstvo ni nobenega delovnega mesta.

Razlixne stopnje mobilnosti prebivalstva so razvidne tudi iz podatka, da je 65 ali $7,1 \%$ k.o. z indeksom nad 100 in 72 ali 7,9 \% k.o. z indeksom od 50 - 100, medtem ko ima 326 k.o. ali 35,7 $\%$ indeks od 10 - 50, kar polovica k.o (451 ali 49,23\%) pa od 0 - 10.

\section{ZAPOSLENI V SV SLOVENIJI GLEDE NA ZAPOSLITEV V KRAJU BIVANJA, V DRUGEM KRAJU $V$ OBČINI IN $V$ DRUGIH OBČINAH $V$ SLOVENIJI}

Tudi zaposlitev $\mathrm{z}$ vidika administrativne razdelitve na obðine omogoca zanimive ugotovitve. $\mathrm{V}$ SV Sloveniji je bilo zaposlenih leta 1981192.066 oseb, pri čemer so zajeti zaposleni v neagrarnih dejavnostih in družbenem sektorju kmetijstva. $\mathbf{V}$ kraju bivanja je bila zaposlena tretjina zaposlenih, druga tretjina $v$ drugih krajih obæine in tretja v drugih obđinah v Sloveniji. Precejšnja odstopanja se pojavljajo že med subpanonsko in subalpsko makroregijo, కe večja pa med mezoregijami (tabela 2). Medtem ko je v obeh makroregijah delež zaposlenih v kraju bivanja približno enak in znaša okrog tretjine zaposlenih, je $\mathbf{v}$ subpanonski makroregiji zaposlenih $\mathbf{v}$ drugem kraju obðine precej manj, v drugih obðinah Slovenije pa veð oseb kot pa v subalpski makroregiji.

Med mezoregijami imajo najmanj zaposlenih v kraju bivanja Dravsko obmejno hribovje (7,5 $\%)$, Haloze (11 \%), Pohorje (18,7 \%), Slovenske gorice $(18,8 \%)$ in Dolisko-Vitanjsko podolje $(15,6 \%)$. Tako nizke vrednosti pa se pojavljajo tudi v nekaterih submezoregijah, npr. Zahodnih Slovenskih goricah $(11,3 \%)$, na Dravskem polju $(12 \%)$ in v nekaterih mikroregijah, npr. na Gori夭kem (11,5\%), Dolinskem (15,6\%) in Apaßkem polju (16,9\%).

Druga obmoxja sicer razlǐ̌nih hierarhið̌nih stopenj izkazujejo nasprotno zelo visok delež zaposlenih v kraju bivanja. Mednje sodijo Mariborska mestna regija (43,3\% oz. 21.031 oseb), MežiSka (47,3\%) in Mislinjska dolina (41,9 \%), Ptujsko polje (44,6 \%), Lendavske gorice (51,7 \%), Mursko polje (39,9\%) in Ravensko (51,7\%).

Med obcinami imata najmanj zaposlenih v kraju bivanja obxini Lenart $(17,6 \%)$ in Maribor Pesnica (14,4\%), najve飞 pa imajo obðine Ravne na Koroskem (47,5\%), Slovenj Gradec (37,1 $\%$ ), obcina Maribor v sedanjem obsegu (34,3\%), Murska Sobota (37,4\%), Slovenske Konjice 
$(37,7 \%)$ in Gornja Radgona (37 \%).

Vpogled $\mathrm{v}$ mobilnost prebivalstva omogođajo tudi katastrske obðine $\mathrm{z}$ ustreznim deležem zaposlenih. Od 749 k.o. v subpanonski SV Sloveniji jih je 562 ali $75 \%$ z manj kot $10 \%$ zaposlenih $\mathbf{v}$ kraju bivanja, v subalpski pa od 196 k.o. 126 ali 64,3\%. Vecjih odstopanj po regijah ni. Višji deleži so znaxilni le za zaposlitvene centre (karta 2 ). Nad $80 \%$ zaposlenih v drugem kraju obCine ugotavljamo v 20,4\% k.o. subpanonske in 23,5\% k.o. subalpske SV Slovenije. Pri tem izrazito izstopajo Pomurje, ptujsko, slovenskobistriško in ravensko obmožje. Posebno veliko je takšnih k.o. v Prekmurskih goricah $(62 \%)$ in na Prekmurski ravnini $(65,8 \%)$ oziroma v obxinah Ravne (59 \%), Murska Sobota (68,9 \%), Lendava (44,1\%), Ljutomer (42\%) in Slovenske Konjice $(45,2 \%)$. Kot obmoðje z manj kot $40 \%$ zaposlenimi v drugem kraju obxine pa izstopa zlasti mariborsko zaposlitveno obmođje; obCina Maribor Pesnica celo z 82,1\% k.o.

Z vec kot $40 \%$ zaposlenimi v drugih obcinah v Sloveniji je v subpanonski SV Sloveniji 35,5 $\%$, v subalpski 31,6 \%, na Dravskem polju $74,5 \%$ in v Zahodnih Slovenskih goricah celo 82,7 $\%$ k.o. Znaxilen je torej vpliv zaposlitvenega obmoxja Maribora; to kažeta tudi obxini Lenart $(83,9 \%)$ in Maribor Pesnica $(78,6 \%)$. Na Koroškem ima podobnom vlogo obæina Dravograd $(80 \%)$.

Če izlocimo primarni sektor zaposlitve in razvrstimo k.o. po številu delovnih mest na veð skupin, z najnižjo do 20 in najvisjo nad 500 delovnimi mesti, ugotovimo, da je k.o. z najnižjo kategorijo v subpanonski SV Sloveniji $45,7 \%$, v subalpski celo $65,3 \%$. Najvišje vrednosti kažejo Prekmurske gorice (91,1 \%), Ravensko $(89,7 \%)$, Slovenske gorice $(85,7 \%)$, Haloze $(87,7 \%)$ in Dravsko obmejno hribovje (87,9 \%); med obcinami pa Ormož, Ptuj, Murska Sobota, Ljutomer, Lenart, Maribor Pesnica in Ravne. Nasprotno imajo najvišji delež k.o. z več kot 500 zaposlenimi Mariborska mestna regija (100 \%), Dravska (23,6 \%) in Mežiška dolina (12,2 $\%$ ); med obxinami pa obmoxje sedanje obxine Maribor (18\%), obðine Dravograd (20\%), Ravne (12,8 \%) in Radlje ob Dravi (10,3\%). Znacilna je torej velika pogostost krajev z majhnim številom delovnih mest in moxno koncentracijo le-teh $\mathbf{v}$ manjక̌em številu krajev. Vmesne kategorije so namre夭̌ zelo slabo zastopane (tabela 3 , karta 3 ).

Najpomembnejక̌e zaposlitveno območje predstavlja Mariborska mestna regija s 64.071 delovnimi mesti, sledijo Murska Sobota (14.315), Ptuj (11.170), Ravne (6.386), Slovenska Bistrica (5.002), Slovenj Gradec (4.885), Lendava (4.315), L jutomer (3.840), Gornja Radgona (3.829) in Prevalje (2. 180). Preostali kraji imajo manj delovnih mest. 


\section{LITERATURA IN VIRI}

Vobovnik F., 1991, Naselja v SV Sloveniji po stevilu aktivnih prebivalcev in Stevilu delovnih mest leta 1981 (diplomska naloga, Pedagoska fakulteta Maribor)

Popis prebivalstva 1981, Aktivni prebivalci glede na naselje dela in naselje bivališ̌a (rađunalni\ki izpis), Zavod SR Slovenije za statistiko, Ljubljana (statistična in kartografska obdelava Augustinovix D., Horvat U, Vobovnik F., Pedagoška fakulteta Maribor, 1991)

\section{DISTRIBUTION OF POPULATION IN THE NORTH-EASTERN PART OF SLOVENIA FROM THE POINT OF VIEW OF DWELLING AND WORKING PLACE}

The article evaluates the relation between the number of active population regarding the dwelling and working place in the year 1981 with the purpose of finding out the population mobility. It evaluates also the working place with respect to the fact, whether it is identical with the dwelling place or whether the working place is situated in another community place and/or in other Slovene communities. The analysis refers to more than 900 cadastral communities (further c.c.) in the north-eastern part of Slovenia and its regional distribution.

The regions with an index over 100 represent the areas with bigger number of working places than active population and into these regions the working migrations are primarily strongly directed. There is no area with an index under 20 , however, there exists a great number of c.c. out of which the greater part of population is looking somewhere else for a job. There are 85 or $7,1 \%$ of c.c. with an index above 100 in the north-eastern part of Slovenia, 72 or $7,9 \%$ of c.c. with an index from $50-100,326$ or $35,7 \%$ of c.c. with an index from $10-50$ and at least half of c.c. have an index from $0-10$ (table 1, map 1).

One third of the employed works in their dwelling places, the second third in other community places and the last one in other Slovene communities. $73 \%$ of c.c. have less than $10 \%$ of those employed in their dwelling places. More than $80 \%$ the employed in another community place are stated in $29 \%$ of c.c., whereas there are $35 \%$ of c.c. with more than $40 \%$ the employed in other Slovene communities (table 2, map 2).

At least $70,9 \%$ of c.c. have less than 20 working places. Strong concentration of working places appears only in a smaller number of settlements (table 3, map 3). 
Tabela 1

Aktivno agramo in neagrarno prebivalstvo glede na kraj bivanja in kraj zaposlitve v SV Slovenij̈ leta 1981

Vsi aktivni preb. Akt.agrar.p. Aktivno neagrarno prebivalstvo

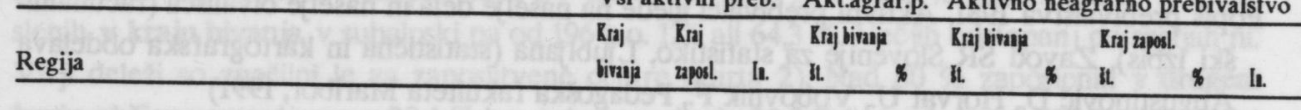

\section{A - SUBPANONSKA SV SILOVENUA \\ 1 - PREKMURSKE GORICE \\ 1a1 - Gorixko \\ 1a2 - Lendavske gorice}

2 - POMURSKA RAVNINA

2a - PREKMURSKA RAVNINA

2a1 - Ravensko

2a2 - Dolinsko

b - APAŠKO IN MURSKO POLJE

2 b1 - Apaško polje

$2 \mathrm{~b} 2$ - Mursko polje

3 - SLOVENSKE GORICE

3a - Zahodne Slovenske gorice

3b - Srednje Slovenske gorice

$3 c$ - Vzhodne Slovenske gorice

4 - DRAVSKA RAVNINA

4a - Dravsko polje

4b - Ptujsko polje

5 - HALOZE

6 - DRAVINJSKE GORICE

7 - Mariborska mestna regija

B - SUBAL.PSKA SV SLOVENUAA

8 - DRAVSKO OBMEJNO HRIBOVJE

9 - POHORJE

10 - MISLINJSKA DOLINA

11 - MEŽIŠKA DOLINA

$\begin{array}{rrrrrrrrrr}199019 & 192020 & 96 & 54164 & 27,3 & 14485 & 72,8 & 137760 & 71,7 & 95 \\ 17635 & 16786 & 95 & 11304 & 64,1 & 6331 & 35,9 & 5579 & 33,2 & 88 \\ 14391 & 11832 & 82 & 10830 & 75,3 & 3561 & 24,7 & 1134 & 9,6 & 31 \\ 3244 & 1954 & 152 & 474 & 14,6 & 2770 & 85,4 & 445 & 89,7 & 160\end{array}$

$\begin{array}{llllllllll}37104 & 37631 & 101 & 14034 & 37,9 & 23070 & 62,2 & 23379 & 62,1 & 101\end{array}$

$\begin{array}{llllllllll}30107 & 30092 & 99 & 11702 & 38,9 & 18405 & 61,1 & 18243 & 60,6 & 99\end{array}$

$\begin{array}{llllllllll}117776 & 19646 & 132 & 3721 & 25,2 & 11055 & 74,8 & 15545 & 79,1 & 140\end{array}$

$\begin{array}{llllllllll}15331 & 1046 & 68 & 7981 & 52,1 & 7350 & 47,9 & 2698 & 25,8 & 36\end{array}$

$\begin{array}{llllllllll}6997 & 7539 & 107 & 2332 & 33,3 & 1665 & 66,7 & 5136 & 68,1 & 110\end{array}$

$\begin{array}{llllllllll}1813 & 1178 & 64 & 738 & 40,7 & 1075 & 59,3 & 473 & 40,1 & 4\end{array}$

$\begin{array}{llllllllll}5184 & 6361 & 122 & 1594 & 30,7 & 3590 & 69,2 & 4663 & 73,3 & 129\end{array}$

$\begin{array}{llllllllll}17214 & 34219 & 72 & 17703 & 37,5 & 29511 & 62,5 & 16761 & 48,9 & 56\end{array}$

$\begin{array}{llllllllll}13131 & 7315 & 54 & 3105 & 23,1 & 10326 & 76,9 & 1308 & 58,9 & 41\end{array}$

$\begin{array}{llllllllll}22482 & 18309 & 81 & 8812 & 39,3 & 13640 & 60,7 & 9184 & 51,8 & 69\end{array}$

$\begin{array}{llllllllll}11301 & 8595 & 76 & 5756 & 51,0 & 5545 & 49,1 & 2969 & 34,5 & 53\end{array}$

$\begin{array}{llllllllll}29375 & 25027 & 85 & 5155 & 18,5 & 23920 & 81,4 & 19341 & 77,3 & 80\end{array}$

$\begin{array}{llllllllll}18035 & 10151 & 56 & 2928 & 16,2 & 15107 & 83,8 & 7243 & 18,0 & 47\end{array}$

$\begin{array}{llllllllll}11340 & 14876 & 131 & 2527 & 22,3 & 8813 & 77,7 & 12098 & 81,3 & 137\end{array}$

$\begin{array}{llllllllll}6210 & 4158 & 66 & 3150 & 50,7 & 3060 & 49,3 & 1192 & 28,7 & 38\end{array}$

$\begin{array}{llllllllll}11786 & 9515 & 80 & 2065 & 17,5 & 9721 & 82,5 & 7437 & 78,2 & 76\end{array}$

$\begin{array}{llllllllll}19695 & 64684 & 130 & 453 & 0.9 & 49242 & 99,1 & 64071 & 99,0 & 130\end{array}$

$\begin{array}{llllllllll}13765 & 38378 & 87 & 6361 & 14,5 & 37404 & 85,5 & 32103 & 83,6 & 85\end{array}$

$\begin{array}{llllllllll}10026 & 6942 & 69 & 1704 & 17,0 & 8322 & 83,0 & 5275 & 75,9 & 63\end{array}$

$\begin{array}{llllllllll}15316 & 12420 & 81 & 2761 & 18,0 & 12555 & 81,9 & 9801 & 78,9 & 78\end{array}$

$\begin{array}{llllllllll}6875 & 7017 & 102 & 1092 & 15,9 & 5783 & 84,1 & 5809 & 82,8 & 100\end{array}$

$\begin{array}{llllllllll}11548 & 11999 & 103 & 804 & 7,0 & 1074 & 93,0 & 11218 & 93,5 & 104\end{array}$

\section{SV SLOVENUA}

$\begin{array}{llllllllll}212784 & 230398 & 94 & 60525 & 21,9 & 182259 & 75,1 & 169863 & 73,7 & 93\end{array}$

In. - indeks med št.aktivnih v kraju zaposlitve in St.aktivnih v kraju bivanja 
Tabela 2

Zaposleni v SV Sloveniji glede na kraj zaposlitve in kraj bivanja leta 1981

Število zaposlenih

$\%$ zaposlenih

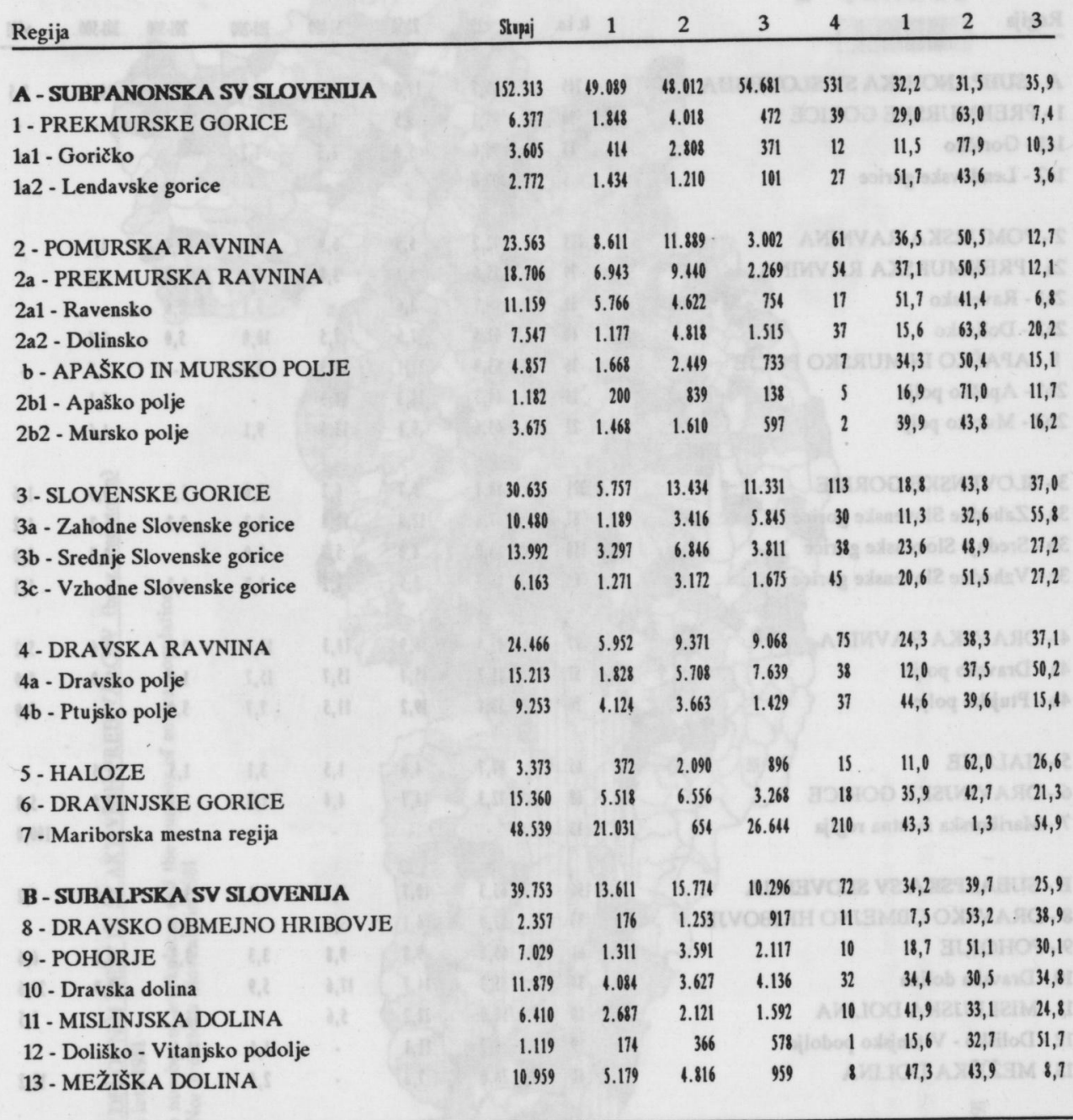

SV SLOVENUA

192.066

62.700

$\begin{array}{lll}63.786 & 64.977 \quad 603\end{array}$

$32,6 \quad 33,2 \quad 33,8$

1-v kraju bivanja 2 -v drugem kraju v obxini 3 -v drugi obxini v Sloveniji 4 -drugod 
Tabela 3

Delež katastrskih obein v SV Slovenije glede na število delovnih mest v neagrarnih dejavnostih leta 1981

\% k.o. glede na število delovnih mest

\section{Regija}

A - SUBPANONSKA SV SLOVERUA

1 - PREKMURSKE GORICE

1a1 - Goricko

$1 \mathrm{a} 2$ - Lendavske gorice

2 - POMURSKA RAVNINA

2a - PREKMURSKA RAVNINA

2a1 - Ravensko

$2 \mathrm{a} 2$ - Dolinsko

b - APAŠKO IN MURSKO POLJE

2 b1 - Apaško polje

2 b2 - Mursko polje

3 - SLOVENSKE GORICE

3a - Zahodne Slovenske gorice

3b-Srednje Slovenske gorice

3c - Vzhodne Slovenske gorice

4 - DRAVSKA RAVNINA

4a - Dravsko polje

4b - Ptujsko polje

5 - HALOZE

6 - DRAVINJSKE GORICE

7 - Mariborska mestna regija

\section{B - SUBAI.PSKA SV SLOVENIJA}

8 - DRAVSKO OBMEJNO HRIBOVJE

9 - POHORJE

10 - Dravska dolina

11 - MISLINJSKA DOLINA

12 - Doliško - Vitanjsko podolje

13 - MEŽIŠKKA DOLINA

\section{I. t..}

$<20$

$21-50$

$51-100$

749

90

85

90,6

100,0

115

79

39

40

40
36

36

14

22

\section{2,2}

75,9

89,7

62,5

63,9

64, 3

63,6

321

$321 \quad 78$

$87 \quad 67,4$

$150 \quad 80,0$

$84 \quad 85,7$

$77 \quad 15,4$

$51 \quad 41,2$

$26 \quad 53,8$

$16,9 \quad 11,3$

15,7

15,7

19,2

15,7

13,3

$13,0 \quad 2$,

11,5

15,1

1,9

$201.300 \quad 301.500$

$>501$

$\begin{array}{cccccccc}65 & 87,7 & 4,6 & 1,5 & 3,1 & 1,5 & 1,5 & = \\ 68 & 72,3 & 14,7 & 4,4 & 1,5 & 1,5 & 2,8 & 5,8 \\ 13 & - & . & - & . & . & - & 100,0\end{array}$

19

$\begin{array}{llllllll}196 & 65,3 & 10,7 & 7,1 & 3,1 & 3,6 & 1,0 & 9,2\end{array}$

$33 \quad 87,9$

6,1

$6,1 \quad 3,0$

$61 \quad 65,6$

$34 \quad 35,3$

9,8

14,7

9,8

(1)

- 3,0

$18 \quad 50,0$

22,2

17,6
5,6

3,3
5,9

3,3

1,2

2,3

0,6

$1,2 \quad 1,2$

966

4178

$$
\text { 11,1 }
$$

1,3 


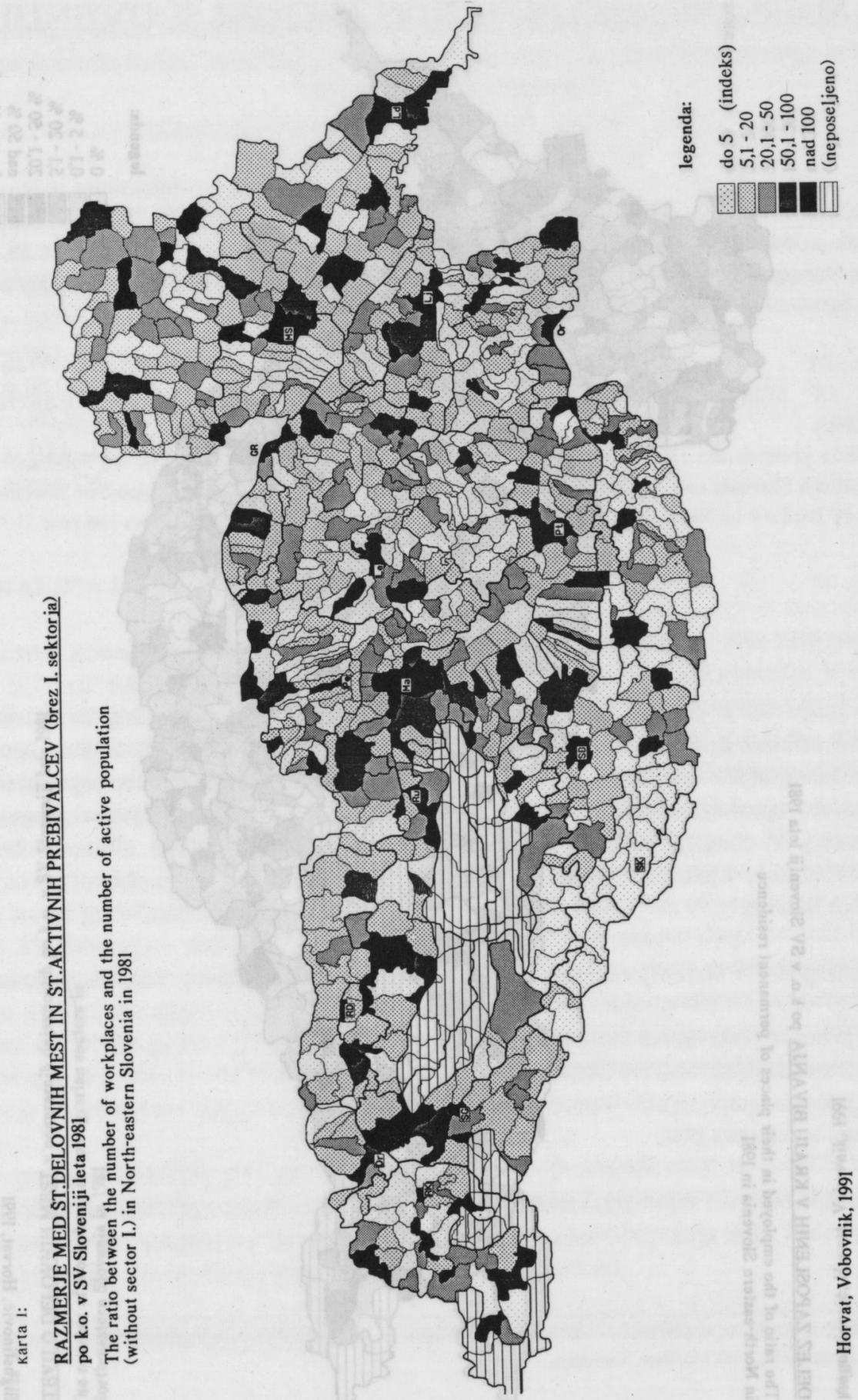




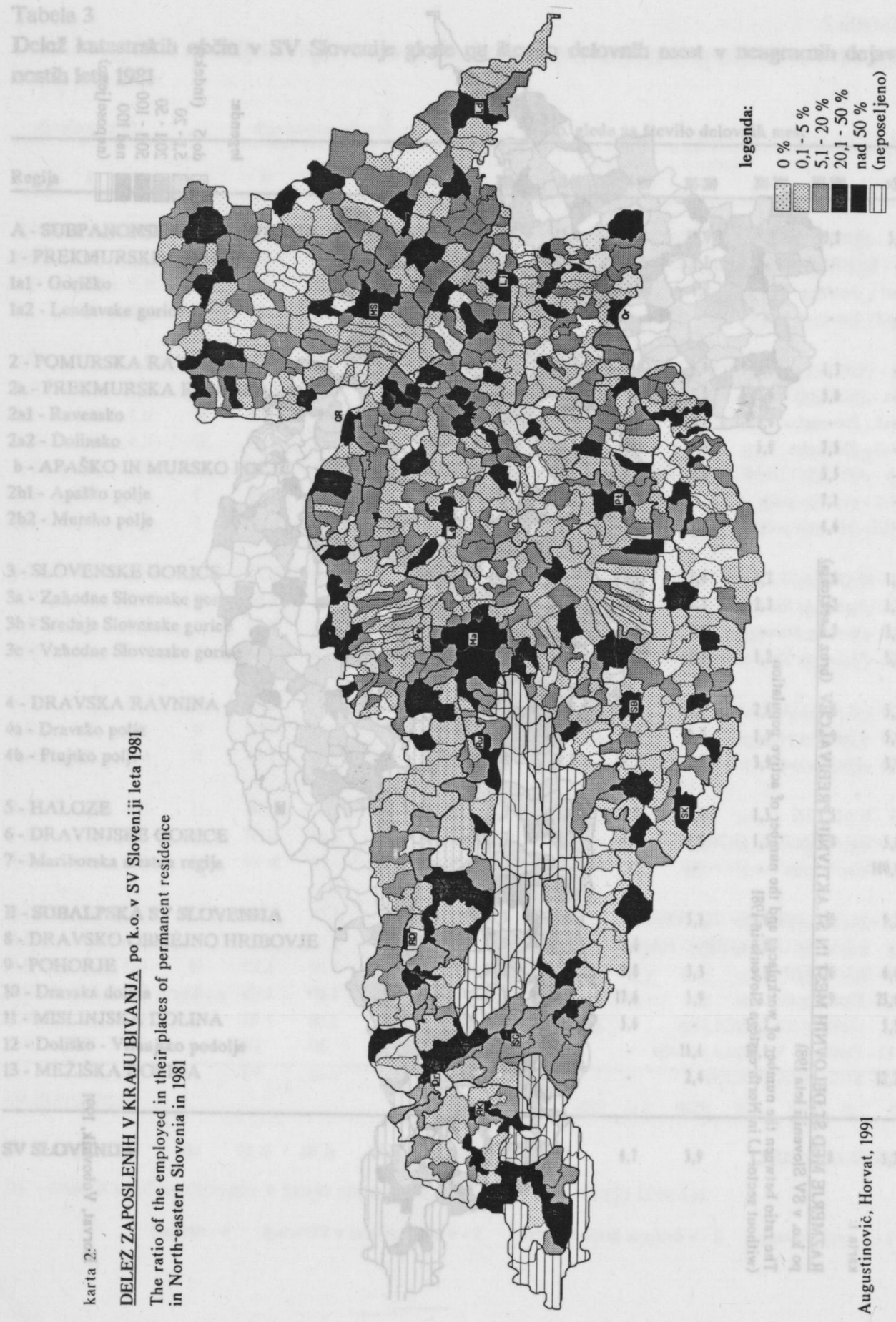




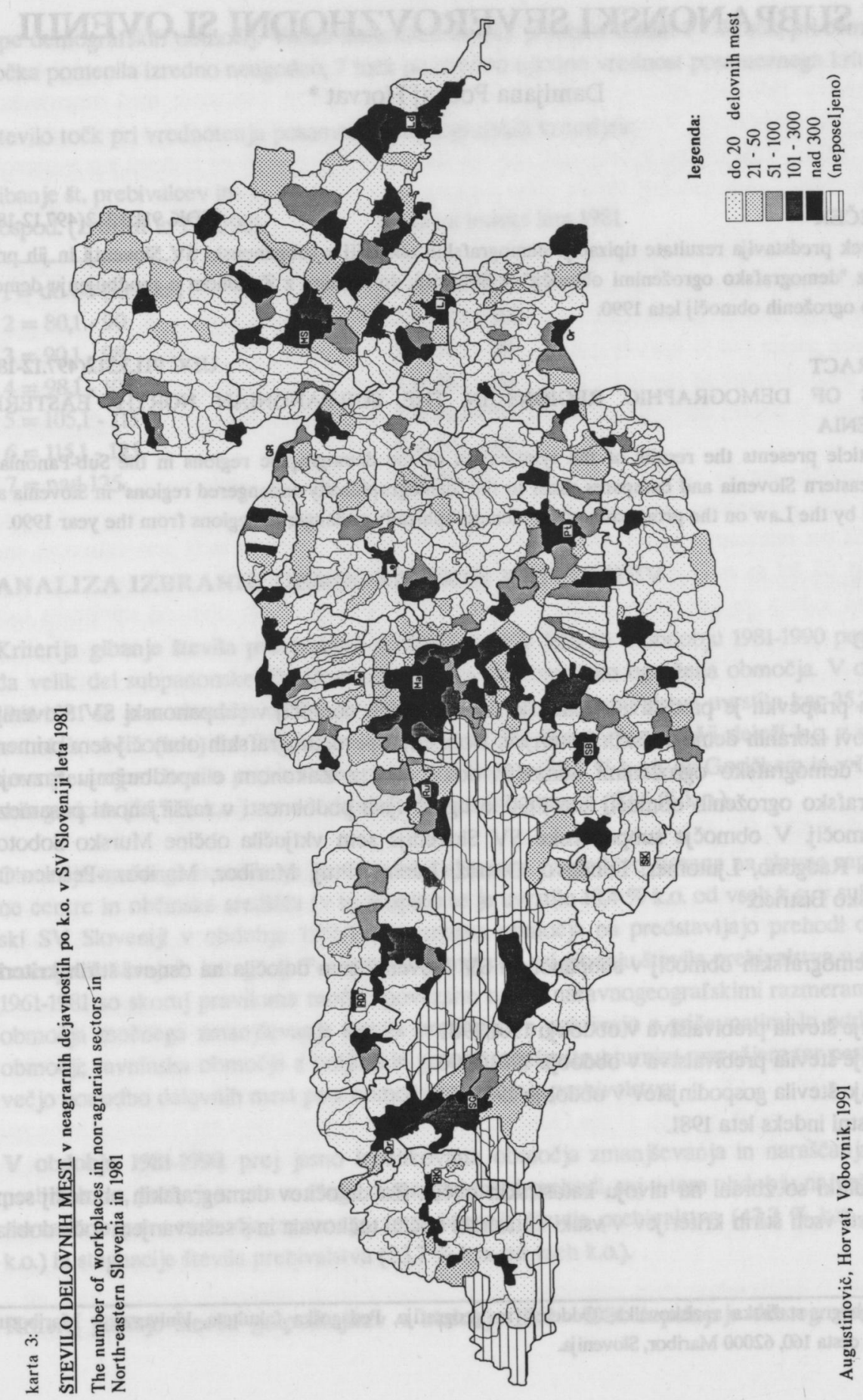

